\title{
MICROSTRUCTURE TRANSFORMATION OF ALPHA-TITANIUM AFTER MECHANICAL AND LASER FORMING
}

\author{
HERMAN FIDDER ${ }^{1,2}$, VACLAV OCELIK ${ }^{2} \&$ JEFF. TH. M. DE HOSSON ${ }^{2}$ \\ ${ }^{1}$ Department of Mechanical Engineering, Cape Peninsula University of Technology, South Africa \\ ${ }^{2}$ Department of Applied Physics, University of Groningen, The Netherlands
}

\begin{abstract}
The effects of microstructure transformation during forming processes viz. Mechanical (contact process via tool and die), laser (contactless process via $\mathrm{CO}_{2}$ laser defocused beam) and a combined process consisting of laser forming followed by mechanical forming was analysed before and after each process. Plastic flow during the deformation is strongly influenced by anisotropy and the work hardening rate, which is due to the limited number of slip planes in a hexagonal close-packed material. Commercially pure titanium can exhibit dominant twinning systems during deformation when either tensile or compression is introduced. Electron backscatter diffraction (EBSD) results show multiple dominate pyramidal slip behaviours due to the lattice rotation when comparing the before and after deformation processes. The Schmid factor and twinning parent/daughter ratios for each individual grain after each forming process were also evaluated. Our findings show twin nucleation and twin growth also contribute a major role when observing the nature of the microstructure for each process.
\end{abstract}

Keywords: commercially pure (CP) titanium, laser forming, EBSD, twinning, pyramidal slip.

\section{INTRODUCTION}

Titanium and titanium alloys are used extensively in many industrial fields due to their good strength-to-weight ratio, corrosion resistance and high strength at elevated temperatures. These material characteristics are highly desirable in many applications, particularly in the aerospace industry. Laser forming which is a relatively new technique, e.g. [1]-[4], allows the modification of shape (curvature) of sheet metal and is thus considered an advanced manufacturing process. The microstructural changes from the received parent plate or substrate to the various forming processes are of particular interest. It plays an important role when considering integrity and durability during the service life of the component. The objective of this study is to compare the microstructural effect of mechanical bending, laser bending and laser/mechanical bending on $\mathrm{CP}$ titanium (Ti) plates using electron backscatter diffraction (EBSD). To the author's knowledge, no work has been published on the characterisation and comparison of $\mathrm{CP}$ Ti subject to the three bending techniques using EBSD data. CP Ti can exhibit dominant twinning systems after deformation when either tensile or compression stresses is introduced on the sample. Studies show the observation of twinning activity on the $\{101 \overline{2}\},\{112 \overline{2}\}$ and $\{112 \overline{1}\}$ planes using EBSD with relation to grain size and grain boundaries [5]-[7]. Additionally, twinning nucleation and twin growth have been reported to relate to grain boundary misorientations in HCP magnesium viz. twinning has a greater possibility to occur at grain boundaries with low angles compared to grain boundaries with high angles [8]. Furthermore, the most common twinning systems for HCP CP Ti can be split into two categories viz. compression and tension twins as shown in Table 1. Furthermore, twinning could give rise to work hardening especially if multiple different twinning systems are present within the grains. 
Table 1: Common twinning systems of HCP Ti.

\begin{tabular}{|c|c|c|c|}
\hline Twinning system & Rotation axis & Rotation angle & Twin type \\
\hline$\{11-21\}<11-2-6>$ & $<1-100>$ & 35.10 & Tension \\
\hline$\{10-11\}<10-1-2>$ & $<11-20>$ & 57.42 & Compression \\
\hline$\{11-22\}<11-2-3>$ & $<1-100>$ & 64.62 & Compression \\
\hline$\{11-24\}<22-4-3>$ & $<1-100>$ & 76.66 & Compression \\
\hline$\{10-12\}<10-1-1>$ & $<11-20>$ & 84.78 & Tension \\
\hline
\end{tabular}

\section{EXPERIMENTAL PROCEDURE}

\subsection{Materials and bending processes}

The substrate material used in this study was CP Ti ASME SB 265-6, grade 2 supplied as annealed $\sim 3 \mathrm{~mm}$ thick plate. The parent material had an average tensile strength of $\sim 430 \mathrm{MPa}$ and yield strength of $\sim 360 \mathrm{MPa}$. Rectangular test samples $(200 \times 50 \times 3 \mathrm{~mm})$ were laser cut from the sheet and subsequently bent by three methods, namely: (i) laser bending (LB), (ii) mechanical bending (MB) and (iii) combined laser/mechanical bending (LB/MB). A $5 \mathrm{~kW} \mathrm{CW} \mathrm{CO}_{2}$ Trumpf laser was used to manufacture plate samples to curvatures of $120 \mathrm{~mm}$ for the LB process and to $240 \mathrm{~mm}$ for the LB/MB application. The laser parameters are shown in Table 2.

The laser 'line-heating' (irradiation) sequence was such that there was a $50 \%$ overlap between consecutive 'line-heating' paths, that is, the defocused beam spot size of $12 \mathrm{~mm}$ resulted in an interval step of $6 \mathrm{~mm}$. For the laser bending process three plate samples were positioned and aligned adjacent to one another having a gap of approximately $2 \mathrm{~mm}$ in-between. The multi-scan 'line-heating' process commenced approximately $31 \mathrm{~mm}$ from either end, alternating between ends according to the interval step indicated, with the final scanned location being in the centre of the plate sample. This is considered by the authors as an 'outside-in' irradiation sequence. Each location was irradiated 6 times (scanning cycle) before the laser head was moved to the next location. Mechanical bending to the same radii as the laser process was performed using a tool and die press machine. The press machines' tool has a curvature of $\sim 118.5 \mathrm{~mm}$ whilst the die has a curvature of $\sim 121.5 \mathrm{~mm}$ so that the mechanical formed specimen has a mean radius of $\sim 120 \mathrm{~mm}$. In the case of the combined laser/mechanical application, the plates were first bent to a radius of $\sim 240 \mathrm{~mm}$ by laser and further bent to $\sim 120 \mathrm{~mm}$ by the mechanical process. All plate samples were bent about the length of the plane.

\section{RESULTS AND DISCUSSION}

Considering the microstructural changes, it has been shown that the resulting microstructure of Ti6Al4V alloy in the region of the scan line may be unacceptable by aircraft industry standards unless secondary processing is performed [9]. In the current study, all three categories of variables were essentially kept constant, i.e. sample thickness, sample length and overall radii of $120 \mathrm{~mm}$. The experimental work presented in this paper considered only one set of laser parameters as shown in Table 2. 
Table 2: Laser bending parameters.

\begin{tabular}{|c|c|c|c|c|c|}
\hline $\begin{array}{c}\text { Radius of } \\
\text { Curvature } \\
(\mathrm{mm})\end{array}$ & $\begin{array}{c}\text { Power } \\
(\mathrm{kW})\end{array}$ & $\begin{array}{c}\text { Scanning } \\
\text { speed } \\
(\mathrm{m} / \mathrm{min})\end{array}$ & $\begin{array}{c}\text { Beam } \\
\text { overlap } \\
(\%)\end{array}$ & $\begin{array}{c}\text { No. of scans } \\
\text { per location }\end{array}$ & $\begin{array}{c}\text { No. of } \\
\text { locations }\end{array}$ \\
\hline 240 & 1.5 & 1.8 & 50 & 6 & 23 \\
\hline 120 & 1.5 & 1.2 & 50 & 6 & 23 \\
\hline
\end{tabular}

\subsection{Metallography}

The microscopy of commercially pure titanium can be very complex because titanium undergoes an allotropic phase transformation where alpha-phase transforms to beta-phase [10]. Thus, depending on processing, the microstructure of titanium can vary widely. The analysis performed in this research shows the substrate (Fig. 1) and the change in substrate microstructure by application of the deformation processes (MB, LB and LB/MB) (Fig. 2-Fig. 4). Fig. 1 (top and bottom) shows EBSD data of the microstructure of the substrate material consisting of equiaxed and fully recrystallised $\alpha$-phase grains with an average grain diameter of $\sim 100 \mu \mathrm{m}$. Deformation twin systems $\{10-12\}<10-4-4>84.7^{\circ}$ (tension) can be observed together with small traces of the $\{11-22\}<11-2-3>64.3^{\circ}$ compression twins which could be due to the manufacturing processes. Fig. 2 (top and bottom) shows EBSD results of the MB process which illustrates a significant increase of deformation twins. The top (inner) radius shows that the bulk of the twinning was found to be at a depth of approximately $400 \mu \mathrm{m}$ from the top surface. The majority twinning deformation system was the $\{11-22\}<11-2-3>64.3^{\circ}$ compression, while a minor of $\{11-24\}<22-4-3>76.7^{\circ}$ compression and $\{10-12\}<10-1-4>84.7^{\circ}$ tension twins were present.

For the bottom (outer) section of the MB process, the bulk deformation twinning was found to be at a depth of approximately $500 \mu \mathrm{m}$ from the outer bottom surface. The majority twinning deformation system was the $\{10-12\}<10-1-1>84.7^{\circ}$, while a minor twinning system was found to be $\{11-21\}<11-2-6>34.8^{\circ}$. Fig. 3 shows the LB process (top and bottom) that were subjected to high temperatures during the laser bending process which resulted in rapid heating and cooling rates that affected the microstructure of the titanium. As a consequence the morphology of the $\alpha$ - phase changed and the presence of acicular $\alpha$-plates were observed through the plate thickness. Titanium alloys (Ti6Al4V) investigated by [9], revealed that oxygen uptake during processing in air contributes to the formation of an $\alpha$-phase and an increase in micro-hardness on the irradiated surface.

Furthermore, random grains exhibit grain boundaries with similar properties as twinning, more specifically the $\{10-12\}<10-1-2>57.4^{\circ}$ compression twin. A small amount of $84.7^{\circ}$ and $34.7^{\circ}$ tension twinning systems can also be seen throughout the bottom section which could be due to the cooling rate and deformation during the positive bending process.

Fig. 4 top and bottom shows plates that were bent by the combined method (LB/MB). Fig. 4 top shows that the microstructure of the near-inner surface (curve) was similar to the microstructure observed in the plates deformed only by application of the laser beam (Fig. 3). Acicular $\alpha$-plates were observed to a depth of approximately $750 \mu \mathrm{m}$. 

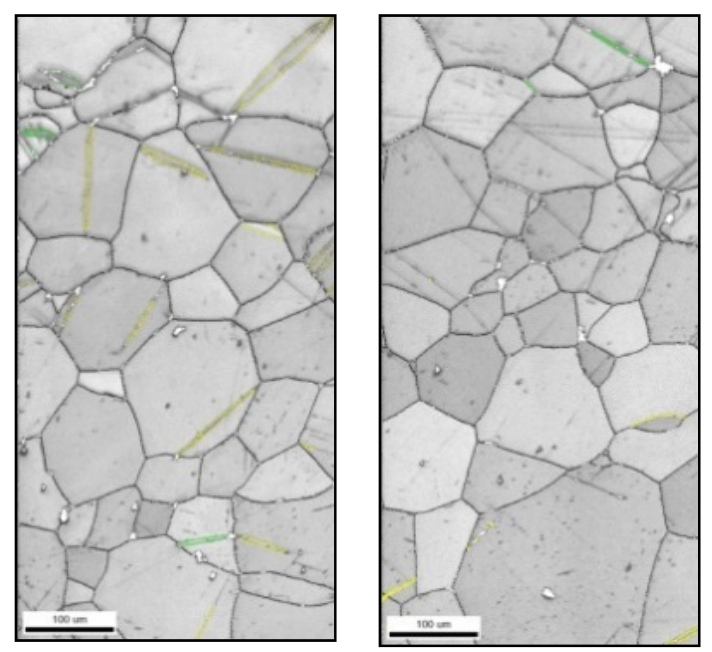

$\begin{array}{cccc}\frac{\text { Plane Normal }}{11-20} & \frac{\text { Direction }}{11-20} & \frac{\text { Angle }}{84.8^{\circ}} \\ -1100 & & -1100 & 64.3^{\circ}\end{array}$

Figure 1: EBSD of substrate, top (left) and bottom (right) showing active twinning due to manufacturing processes.

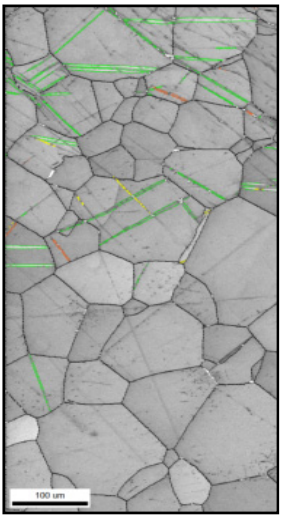

Plane Normal

\section{$-1100$}

$1-100$

$11-20$

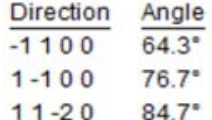

$11-20 \quad 84.7^{*}$

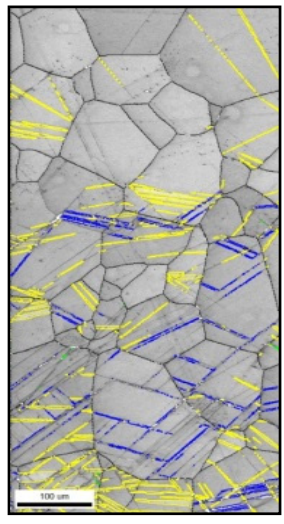

\begin{tabular}{|c|c|c|c|}
\hline & Plane Normal & Direction & Angle \\
\hline & -1100 & -1100 & $\overline{64.3^{\circ}}$ \\
\hline & -1100 & -1100 & $34.8^{\circ}$ \\
\hline & $11-20$ & $11-20$ & 84.7 \\
\hline
\end{tabular}

Figure 2: EBSD results of MB, top (left) and bottom (right) showing twinning systems due to the MB deformation process. 


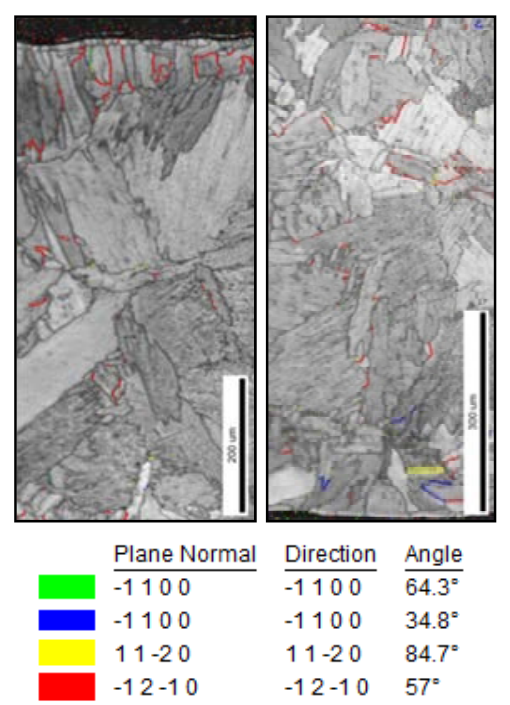

Figure 3: EBSD results of LB, top (left) and bottom (right) showing active of twinning systems due to deformation.
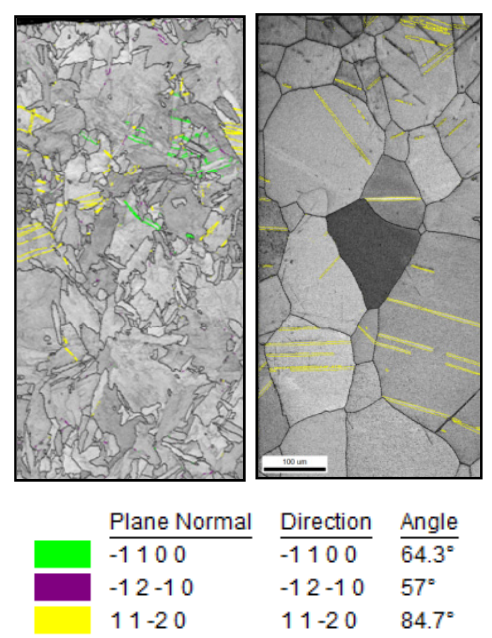

$\begin{array}{ll}\frac{\text { Direction }}{-1100} & \frac{\text { Angle }}{64.3^{\circ}} \\ -12-10 & 57^{\circ} \\ 11-20 & 84.7^{\circ}\end{array}$

Figure 4: EBSD results of $\mathrm{LB} / \mathrm{MB}$, top (left) and bottom (right) showing twinning systems due to LB deformation.

The most active twins for the top section was the tensile $\{10-12\}<10-1-1>84.7^{\circ}$ system with the minority of $\{11-22\}<11-2-3>64.3^{\circ}$ and $\{10-12\}<10-1-2>57.4^{\circ}$ compression twin systems. The regions below the heated surface (bottom) were not affected by the laser energy and therefore, the equiaxed $\alpha$-grains were preserved. A low density of twins was observed in the outer surface of the plate due to mechanical bending performed in the second step of the 
deformation process, however, only $\{10-12\}<10-1-1>84.7^{\circ}$ tensile twin systems were present.

\subsection{Distribution of twins and Schmid factor}

The Schmid factor was calculated for the top section of the MB process for each individual grain that contained twinning and some grains that did not contain twinning but still had a global Schmid factor of 0.35 or higher. For individual grains that contained only twinning with a Schmid factor ranging from 0 (blue) to 0.5 (red) is shown in Fig. 5. In Fig. 5, A represents grains that only contained twinning of $84.7^{\circ}$, For B, C and D the values are $64.7^{\circ}, 84.7^{\circ}+64.7^{\circ}$ and $76.7^{\circ}+64.7^{\circ}$, respectively. The majority of the twinning systems show correlation between the presence of twinning and the Schmid factor number of each individual grain i.e. an increase in Schmid factor gives rise to the number of twinning present. Grains which contain a single or multiple twinning system, have a spread of approximately $4 \%$ to $11 \%$ on area covered within an individual grain, with the $\{11-22\}<11-2-3>64.7^{\circ}$ compression twinning system being the most dominant (Fig. 5B). Additionally, the $64.7^{\circ}$ twinning system tend to broaden up more compared to the $\{10-12\}<10-1-4>84.7^{\circ}$ and $\{11-24\}<22-4-3>76.7^{\circ}$ twinning systems.

The twinning distribution was also recorded for the bottom section of the MB processes. Only tensile twinning systems were present which contain only $\{10-12\}<10-1-1>84.7^{\circ}$ or $\{11-21\}<11-2-6>34.8^{\circ}$ twins and a combination of $\{10-12\}<10-1-1>84.7^{\circ}$ and $\{11-21\}<11-2-6>34.8^{\circ} 34.7^{\circ}$ twins. A spread of approximately $5 \%-36 \%$ of area consumed by twinning within an individual grain is observed, however, $34.7^{\circ}$ and $34.7^{\circ}+84.7^{\circ}$ twin systems ranged between $5 \%-15 \%$. When only the $\{10-12\}<10-1-1>84.7^{\circ}$ twin was present within an individual grain, it tended to occupy more area by broadening as the Schmid factor increased.

\section{CONCLUSIONS}

In this study three deformation methods were employed to bend $\mathrm{CP}$ pure titanium plate samples. EBSD microstructural-crystallographic characterisation technique was used to compare their effects in terms of microstructure behaviour before and after each forming processes for the top/inner and bottom/outer sections.

A

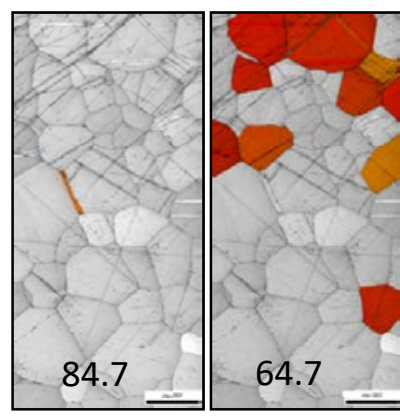

$\mathrm{C}$

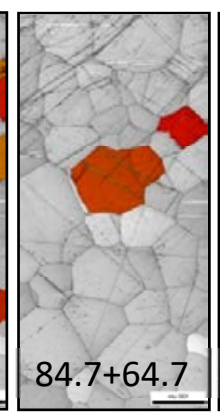

$\mathrm{D}$

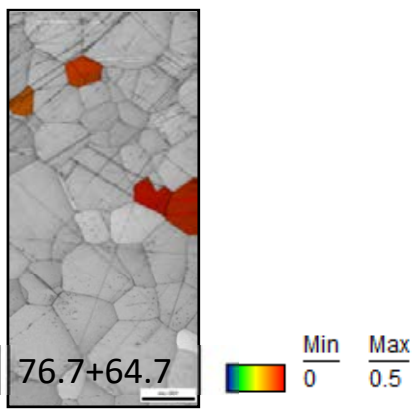

Figure 5: Twinning systems and Schmid factor distribution for the top section that experienced dominant compression during mechanical forming process. 
The MB processes shows an significant increase in twinning which was due to the fast forming process $(\sim 0.547 / \mathrm{sec})$ for both top and bottom section. The LB processes changed the microstructure from a $\alpha$-phase to an acicular $\alpha$-plate like structure. Furthermore, random grains exhibits grain boundaries with similar properties as twinning throughout the specimen. This could be due to the complex forming technique the specimen experienced during the heating and cooling cycle which could give rise to multiple microstructural changes i.e. slip, grain fragmentation, recovery, grain boundary slide and beta to alpha transformation. The combination processes $(\mathrm{LB} / \mathrm{MB})$ exhibited similar properties to that of the $\mathrm{LB}$ for the top section (acicular $\alpha$-plate like structure) and MB for the bottom section (equiaxed acicular $\alpha$ phase) with an increase in twinning for both when comparing it to the substrate.

Due to the LB process exhibiting less twinning within the microstructure, it may be that the LB process will be more beneficial to fatigue properties compared to the MB process. On the other hand, the MB process outperforms LB process during high cycle fatigue when high internal stresses are present. Future studies may involve an investigation into more direct comparison between the LB and MB processes by first subjecting the LB specimens to stress relaxation.

\section{ACKNOWLEDGEMENTS}

The first author wishes to thank the Erasmus Mundus EU-SATURN scholarship for financial assistance as well as Dr A. Botes for her assistance in the experimental forming procedures of the specimens.

\section{REFERENCES}

[1] Els-Botes, A., McGrath, P.J. \& Pienaar, H.J., Bending behaviour of laser-formed high-strength low-alloy (HSLA) steel sheet. R\&D Journal, 23(1), pp. 35-38, 2007.

[2] Els-Botes, A., Fidder, H., Woudberg, S. \& McGrath, P.J., Mechanical characterisation of the effect of various forming processes applied to Commercially Pure Titanium, Materials Characterization. 96, pp. 206-212, 2014.

[3] Fidder, H., Botes, A., Woudberg, S. \& McGrath, P.J., Characterization of microstructure and fatigue life of CP titanium grade 2 specimens subject to various bending processes. In: Surface effects and contact mechanics VI, Proceedings of the $6^{\text {th }}$ International Conference on Contact and Surface, WIT Press: UK, pp. 25-33, 2013.

[4] Fidder, H., Els-Botes, A., Woudberg, S., McGrath, P.J., Ocelik, V. \& De Hosson, J.T.M., A study of microstructural fatigue and residual stress evolution in titanium plates deformed by mechanical and laser bending. In: Contact and Surface. Proceedings of the $12^{\text {th }}$ International Conference on Computational Methods and Experiments in Surface and Contact Mechanics including Tribology, WIT Press: UK, pp. 23-34, 2015.

[5] Beyerlein, I.J., Capolungo, L., Marshall, P.E., McCabe, R.J. \& Tome, C.N., Statistical analysis of deformation twinning in magnesium. Philosophical Magazine, 90(16), pp. 2161-2190, 2010.

[6] Beyerlein, I.J., McCabe, R.J. \& Tome, C.N., Effect of microstructure on the nucleation of deformation twins in polycrystalline high-purity magnesium: A multi-scale modeling study. Journal of mechanics and Physics of solids, 59(5), pp. 988-1003, 2011.

[7] Tome, C.N., Beyerlein, I.J., Wang, J. \& McCabe, R.J., A multi-scale statistical study of twinning in magnesium. Journal of The Minerals, Metals \& Materials Society (TMS), 63(3), pp. 19-23, 2011. 
[8] Capolungo, L., Marshall, P.E., McCabe, R.J. \& Beyerlein, I.J., Nucleation and growth of twins in Zr: A statistical study. ActaMaterialia, 57(20), pp. 6047-6056, 2009.

[9] Watkins, K.G. et al., Laser forming of aerospace alloys. Proceedings of the SAE Aerospace Manufacturing Technology Conference, Seattle, United States of America, Paper no: 2001-01-2610, 2001.

[10] Polmear, I.J., Light Alloys: Metallurgy of the light metals, Edward Arnold Publishers: London:, pp. 19-84, 1981. 